\title{
Young People's Well-Being and the Association with Social Capital, i.e. Social Networks, Trust and Reciprocity
}

\author{
Minna Tuominen ${ }^{1}$ (D) $\cdot$ Leena Haanpää ${ }^{2}$
}

Accepted: 13 July 2021 / Published online: 28 July 2021

(c) The Author(s) 2021

\begin{abstract}
The paper explores the association between social capital of young people at 12-13 years and their subjective well-being using Finland's sub-sample of the third wave of the International Survey of Children's Well-Being. Despite much previous research on this topic, relatively little knowledge is accumulated given that different studies define and measure social capital differently. In line with Robert Putnam, we understand social capital as a combination of social networks, trust, and norms of reciprocity. We measure well-being with two context-free scales: a one-dimensional overall life satisfaction scale and a fivedimensional Student's life satisfaction scale. The analysis is done with linear and unconditional quantile regression. The results indicate that all three dimensions of social capital are significantly associated with well-being. Of the three, trust is the strongest predictor explaining over $30 \%$ of the variance in both well-being scales. The study demonstrates the relevance of considering all dimensions of social capital together to avoid unobserved variable bias. Quantile regression reveals that while social capital is important for well-being across the quantiles, it is particularly important for the youth who fare poorly otherwise. Family-related variables showed the strongest association with well-being while relationships with friends, schoolmates, teachers, and other people mattered considerably less.
\end{abstract}

Keywords Well-being $\cdot$ Social capital $\cdot$ Social networks $\cdot$ Reciprocity $\cdot$ Trust $\cdot$ Young people

\section{Introduction}

It is during our adolescent years that we consolidate our social selves (Coleman \& Hendry, 1999). During this period, interest in other people increases, and friendship and peer relationships in general gain greater importance (Choudhury et al., 2006).

This paper explores how important not only social relationships but social capital, in general, is for the well-being of young people at 12-13 years of age. Social capital has

Minna Tuominen

mtuomine@utu.fi

1 Department of Social Research/INVEST Research Flagship Center, University of Turku, Turku, Finland

2 Department of Social Research/Social Work, University of Turku, Turku, Finland 
stimulated much research and it has been associated with a range of positive outcomes, including better school performance (Lindfors et al., 2018), pro-social behaviour (Jenkins \& Fredrick, 2017), and well-being (Addae, 2020; Bae, 2019; Geraee et al., 2019; Ko \& Kuo, 2009; Lau \& Li, 2011; Laurence, 2019; Morgan et al., 2012; Yoo, 2019), to name a few. Although most researchers have found a positive relationship between social capital and well-being, the evidence is fragmented as many studies have interpreted social capital narrowly, often equalling it to mere social relationships.

In this paper, we adopt Robert Putnam's three-dimensional definition according to which social capital consists of (1) social relations, (2) trust in other people, and (3) norms of reciprocity (Putnam, 2000). In this view, a person is well-off in terms of social capital if she/he sustains good relationships with family, friends, and acquaintances; considers other people generally trustworthy; and provides help to others and receives help from them with ease.

Our study is inspired by Tamar Dinisman and Asher Ben-Arieh's paper from 2016 (henceforth DBA), which explores the characteristics of well-being among young people across 14 countries. Using age, gender, country of living, and access to specific material goods as predictors, they explain up to $11-20 \%$ of the variance in well-being. We build on their results by adding social capital to the model. Alike DBA, we use the Children's Worlds -survey data but only the subset of Finland, which includes variables related to all three dimensions of social capital.

Finland in itself is an interesting case as both young and adult Finns have repeatedly reached some of the highest scores in global well-being/happiness assessments (e.g. Helliwell et al., 2020; Rees, 2017; Ottova-Jordan et al., 2016). ${ }^{1}$ While the use of a one-country sample alone restricts our possibilities of drawing conclusions at a more global level, this is to our knowledge one of the few datasets, which allows measuring Putnam's three social capital dimensions together.

\section{Social Capital Theories}

Each of the three most prominent social capital theorists-Pierre Bourdieu, James Coleman, and Robert Putnam - formulated a distinct definition for it, which partly overlap, but also bear important differences. We go briefly through the three definitions in part to point out some often-repeated misunderstandings, in part to justify our choice adopted in the present paper.

\subsection{Bourdieu's Perspective}

Bourdieu was the first one of the three to write about social capital. Strongly influenced by Marxist theory, he defined social capital in somewhat utilitarian terms as being the sum of actual or potential resources that one can accrue through his/her friends and acquaintances (Bourdieu, 1986). Hence, the volume of one's social capital "depends on the size of the network of connections he can effectively mobilize and on the volume of capital

\footnotetext{
${ }^{1}$ Happiness and life satisfaction are often taken as synonyms to well-being and are being used interchangeably as outcome indicators in well-being-related research. (See e.g. Helliwell \& Putnam, 2004; Campbell et al., 1976; Webster et al., 2021).
} 
(economic, cultural or symbolic) possessed in his own right by each of those to whom he is connected" (Bourdieu, 1986).

In Bourdieu's perspective, networks are established and maintained through chains of exchange of gifts, favours, material resources, etc. ${ }^{2}$ Exchange is the essential element that ties people together. "Exchange transforms the things exchanged into signs of recognition, and through the mutual recognition and recognition of group membership which it implies, re-produces the group" (Bourdieu, 1986). To summarise, for Bourdieu, social capital is an individual resource that consists of two inseparable dimensions: social networks and exchange; the latter is what builds and sustains the former.

\subsection{Coleman's Perspective}

Shortly after Bourdieu, Coleman and Hoffer introduced another version of social capital while researching high school students' educational achievement and school dropout rate. They noticed that the dropout rate was significantly lower in Catholic schools in comparison to other schools and concluded that the closely bound religious community formed a protective resource, social capital (Coleman \& Hoffer, 1987).

For Coleman and Hoffer, social capital is essentially about a network of relationships. The structure of the network is critical for the amount of social capital it can include. A "closure" is a structure where network members know and interact with each other, and a form of closure where older and younger generations share the same values, norms, and sanctions, is what Coleman and Hoffer consider a "functional community" (Coleman, 1988; Coleman \& Hoffer, 1987). ${ }^{3}$

Coleman never specified a clear-cut definition of social capital. Instead, he identified several different expressions of it, including social norms and sanctions, obligations and expectations, trust, and information channels (Coleman, 1988; Coleman \& Hoffer, 1987).

Social norms refer to shared regulations that can, for example, be endorsed by a group of parents and imposed on their offspring. Obligations and expectations are formed between individuals when one person does a favour of some kind to another person. This institutes an obligation, an outstanding "credit slip" that the person placing the initial favour can expect to collect at a given moment. The idea is similar to Bourdieu's chains of exchange. Coleman stresses that obligations and expectations entail trust between people without which there would hardly be any initial gesture of kindness. Trustworthiness means that obligations will be repaid. (Coleman, 1988).

Coleman distinguishes three different contexts where young people's social capital resides. Family-level social capital is revealed in the presence of parents at home and parental interest in their children's lives. School-level social capital arises through the relationships between the students, and between students and teachers. Community-level social capital depends on the structure or the degree of closure that the community members form. A true closure provides a protected setting for making favours that can be expected to be returned, and where joint rules and norms can easily be agreed upon. (Coleman, 1988; Coleman \& Hoffer, 1987).

\footnotetext{
2 In fact, this view is reminiscent of Marcel Mauss' earlier work in Polynesia where he noted that every gift or favour placed an expectation of some form of return (Mauss, 1990).

3 Coleman and Hoffer's interest in the structure of network relates back to Mark Granovetter's (1973) studies of the strength of ties in different network constellations.
} 
In contrast to Bourdieu, Coleman understands social capital as an inherently collective resource that can only exist in relationships between people (Coleman, 1988). His ultimate interest was in educational achievement and he saw social capital as a functional resource of the family and community that could boost young people's school performance. Although appealing particularly for youth researchers, Coleman's version of social capital is challenging mainly for being so loosely formulated (e.g. Lin \& Fu, 2003). Moreover, this version of social capital largely overlooks young people's own investment in building social capital. For Coleman, social capital is essentially an outcome of social structures, not so much of individual behaviour.

\subsection{Putnam's Perspective}

Putnam was the last one of the three scholars to launch his version of social capital. He is much indebted to Coleman for his work, and probably also to Bourdieu, although Putnam hardly ever refers to him. For Putnam "social capital refers to connections among individuals - social networks and the norms of reciprocity and trustworthiness that arise from them" (Putnam, 2000). Many researchers associate overall social norms with Putnam's theory (e.g. Bjørnskov, 2006; Rodríguez-Pose \& von Berlepsch, 2014), and it is true that in his earlier work (1993), Putnam was less clear about what types of norms he was talking about, but in his masterpiece (2000), Putnam explicitly limits the definition to norms of reciprocity. Conversely, social norms relate to Coleman's theory.

Putnam differentiates between formal, organized social networks and informal family and friendship networks. By the same token, Putnam differentiates bonding and bridging social capital. Bonding social capital consists of "inward-looking" relationships that bolster the group identity of homogenous groups and is typically a source of social and psychological support, mutual reciprocity, and solidarity. Bridging social capital, on the other hand, entails an "outward-looking" approach, and consists of relationships with people with more diverse backgrounds that is critical for the exchange of strategic information, for example about job markets. (Putnam, 2000).

Similar to Bourdieu's exchange and Coleman's obligations and expectations, in Putnam's framework, social networks almost inevitably entail reciprocity. Putnam distinguishes specific reciprocity from a more generalized one. Specific reciprocity is about two-way interaction, where a favour done to a friend evokes an expectation, and a moral obligation, to return the favour at some point. That is how reciprocity becomes a norm. Conversely, generalized reciprocity is about helping a person without expecting anything directly in return while trusting that there will always be people to help out when one needs it. (Putnam, 2000).

Trust, the last element of Putnam's three-dimensional social capital, can also be divided between a thicker type of trust that grows from strong and frequent social relations, and a thinner type of trust that relates to people in general. ${ }^{4}$ Thick trust is a necessary building block for bonding social capital, while thin trust contributes to overall law-abiding conduct, active citizenship, and participation in diverse forms of formal networks. (Putnam, 2000). Although institutional and political trust have received plenty of attention among social capital (e.g. Bjørnskov, 2006; Portela et al., 2013; Rodríguez-Pose \& von Berlepsch,

\footnotetext{
4 With the distinction between thick vs. thin trust, Putnam pays explicitly tribute to Mark Granovetter (1973) whose theory about thick and thin ties has clearly marked Putnam's social capital framework.
} 
2014; Rothstein \& Stolle, 2002), Putnam actually identified only social trust, or trust in other people as part of social capital. "Our subject here is social trust, not trust in government or other social institutions. Trust in other people is logically quite different from trust in institutions and political authorities." (Putnam, 2000, emphasis in original text).

Putnam's conceptualization is often interpreted as an account of collective form of social capital (e.g. Portes, 1998; Siisiäinen, 2003). Indeed, in his earlier work on civic engagement in Italy, Putnam explicitly claimed: "One special feature of social capital [...] is that it is ordinarily a public good, unlike conventional capital, which is ordinarily a private good" (Putnam et al., 1993). Yet, in "Bowling Alone" Putnam revised this view: "Social capital has both an individual and a collective aspect [...] Social capital can thus be simultaneously a 'private good' and a 'public good' " (Putnam, 2000). This leaves no doubt that Putnam also recognises social capital as an individual resource.

Putnam focuses mainly on positive outcomes of social capital. In his perspective, social relationships with family, friends, partners, acquaintances, etc. can spawn direct benefits, such as a stronger feeling of self-worth and a greater sense of happiness (Putnam, 2000). Some authors have criticised Putnam for an overly positive approach to social capital and called attention to equally possible negative effects of it (Portes, 1998; Farrell, 2007). While this caution is good to keep in mind, we believe that the average effect of social capital is nevertheless more positive than negative. Just like wealth can become a burden in some circumstances, it is in general considered better to have more than less of it.

Alike Coleman, Putnam also recognises that young people flourish in an environment where people trust each other and frequently interact with each other. He also notes that while children-at-risk are likely to experience deficiencies in social capital, they are also likely to experience the greatest gains if their social capital can be increased. (Putnam, 2000).

In sum, we see many similarities between the three scholars. All of them, relate the idea of exchange/reciprocity tightly to social capital, and both Coleman and Putnam also associate trust to it. Portes considers Bourdieu's theory "arguably the most theoretically refined [one]" (Portes, 1998), but in our view, Putnam, while borrowing elements from both Bourdieu and Coleman, formulated the most comprehensive and yet most specific definition of social capital, thus far.

Some critiques blame Putnam for having put together a too broad concept that combines causes and consequences (Lin \& Fu, 2003; Portes, 1998). For Portes, for example, the essence of social capital is "the ability to secure benefits through membership in networks", while trust and reciprocity are mere causes of it (Portes, 1998). Similarly, Lin understands social capital as "diverse resources embedded in social networks", but he sees social resources and trust as consequences, not causes, of it (Lin \& Fu, 2003).

We agree that Putnam's definition is broad, but like him, we too find social networks, trust and reciprocity, intrinsically interrelated elements, hard to differentiate which comes first, and which follows (as evidenced by opposing views of Portes and Lin about causes and consequences). Social relationships entail some form of reciprocity, or exchange of favours, but that only lasts if one can trust that other persons are there for him/her when the need raises (Putnam, 2000).

In empirical research, Putnam's three dimensions are seldom measured together in one study. Considering, however, the interrelationship between the three, we believe that approaching social capital as a unidimensional resource induces a risk of omitted variable bias and generates potentially misleading results. To verify this assumption, we adopt here Putnam's definition of social capital and test how social networks, social trust and reciprocity, separately and jointly contribute to young people's subjective wellbeing. 


\section{Previous Research on Social Capital and Subjective Well-Being Among Young People}

A myriad of earlier studies have recorded an association between young people's wellbeing and social networks, friendship relationships, family support, etc. (e.g. Haanpää et al., 2019; Parker \& Asher, 1993; Webster et al., 2021; Leme et al.,2015). Although important, we focus here exclusively on studies, which explicitly look into the relationship between social capital and well-being.

In 2006, Kristin Ferguson conducted a systematic review of such studies focusing on family and community social capital, and hence binding her attention to the Colemanian theoretical framework. Ferguson observed that there were major differences in the way the studies operationalized the concept of social capital, but practically all of them found a positive relationship between social capital and well-being. (Ferguson, 2006).

Most studies in Ferguson's review relied on data collected from adult respondents; in them, social capital was seen as something that either the parents or surrounding adults had, or not, and that through them was reflected onto their children (Furstenberg \& Hughes, 1995; Garbarino \& Sherman, 1980; Maccoby et al., 1958; Runyan et al., 1998; Sampson et al., 1999; Stevenson, 1998). Well-being was understood broadly to refer to anything between successful physical and behavioural development to lower levels of violent acts in youth, higher levels of psychological adjustment, and better academic performance.

Our interest resides in the social capital held by young people themselves and its relation with their subjective well-being. We understand subjective well-being as people's own evaluations and aspirations related to their lives (Campbell et al., 1976). As opposed to more objective measures, subjective well-being: (a) is grounded in a person's perceptions and evaluation of his or her experiences; (b) includes positive measures instead of only absence of negative ones; and (c) includes an overall evaluation of life, usually "life satisfaction', (Diener, 1984).

We have identified eight studies that share with us the same research interest. Many of them assess a more complex mechanism where social capital is only one of the potential predictors. For example, Addae (2020) explores the relationship between young people's socio-economic status, social capital, and well-being in Ghana, and Laurence (2019) studies the relationship between community disadvantage, young people's social capital, and well-being in England. Appendix 1 summarises key details of these studies.

All eight studies were conducted in the realm of health sciences, psychology, or in an interdisciplinary setting. Their foremost interest was in well-being, not in social capital, as such. This may explain why many of the studies define social capital only cursorily without relying on any dominant social capital theories. Three of the eight studies use some elements of Putnam's theoretical framework. Two of them deal with the dyad of bonding and bridging social capital (Ko \& Kuo, 2009; Yoo, 2019), while one considers the quality of social networks as an indicator of social capital (Laurence, 2019).

Most of the eight studies operationalise social capital through such dimensions as family social capital (including family sense of belonging, family cohesion, family autonomy and support, family control), friends social capital, school social capital, and/or community social capital (Addae, 2020; Bae, 2019; Geraee et al., 2019; Lau \& Li, 2011; Morgan et al., 2012). Typically, these studies use large batteries of variables to compose a latent factor or a composite index for social capital, but many do not specify the detailed variables used, only the Cronbach's alpha value to evidence the internal reliability of the used scale. Still, the provided information is sufficient to tell that the studies diverge considerably in the way 
they operationalise the concept of social capital (see also Appendix 1). This applies even to those relying on Putnam's theory (Ko \& Kuo, 2009; Laurence, 2019; Yoo, 2019). Notably, none of them applied Putnam's three dimensions of networks, trust, and reciprocity.

There is less variation in the way the studies have operationalised the outcome variable, subjective well-being. The most common ones include some form of happiness/life satisfaction scales (Bae, 2019; Geraee et al., 2019; Ko \& Kuo, 2009; Lau \& Li, 2011; Laurence, 2019; Yoo, 2019) or Cantril's ladder (Addae, 2020; Morgan et al., 2012). Both context-free and domain-specific well-being measures have been used. We observe that models with domain-specific well-being measures run a risk of tautological results if the same model includes related items both as predictors and as part of the outcome variable (e.g. "I like school very much" as part of the satisfaction-scale and "I feel part of my school" or "I feel close to people at school" as predictors).

All eight studies find a significant positive relationship between adolescents' social capital and their subjective well-being (Addae, 2020; Bae, 2019; Geraee et al., 2019; Ko \& Kuo, 2009; Lau \& Li, 2011; Laurence, 2019; Morgan et al., 2012; Yoo, 2019). This is the case even of the three studies that assess the association between social capital and wellbeing in the context of social media (Bae, 2019; Geraee et al., 2019; Ko \& Kuo, 2009).

Only Sung-Man Bae (2019) explores young people's social capital and well-being with a longitudinal research design. Bae focuses on Korean adolescents and finds that a more intense use of smartphones is related to greater social capital over time, and that in turn is related to greater subjective well-being over time. To our knowledge, this is the only study to provide empirical evidence of a causal relationship between young people's social capital and well-being.

\section{Data and Method}

\subsection{Sample and Procedure}

The present study is based on the third wave of the International Survey of Children's WellBeing (ISCWeB: www.isciweb.org), collected in 2018-2019. The survey targeted 8-9, 10-11, and 12-13-year-old primary school students in 35 countries and covered a wide range of themes from home environment and material assets to time use, family relationship, friendships, access to help and support, and subjective well-being. We had an opportunity to include a few additional questions in Finland's questionnaire for the age-group of 12-13 years, i.e. sixth graders to obtain information on the three dimensions of Putnamian social capital. The present study uses this Finnish dataset.

A stratified sampling was conducted based on four major regions (NUTS2) in mainland Finland, as illustrated in the Fig. 1. A random selection of municipalities was conducted according to the proportional number of students in each region making the sample nationally representative of sixth graders. Altogether 29 schools participated in the survey. The proportion of foreign-born students was $4.4 \%$ in the sample (4.0\% in Helsinki-Uusimaa, $5.5 \%$ in Southern Finland, $4.3 \%$ in Western Finland, and 3.1\% in Northern and Eastern Finland) against 5.5\% in the country (Statistics Finland, Population 31.12. by Language, Origin, Year, Sex, Information and Age, referred 31.12.2017). Case weights are used in the analyses to account for the stratified sampling.

Data collection was administered online using the Webropol-survey tool. The ethical committee of the host institution of the authors approved the study protocol in 2018. After 


\section{REGIONAL REPRESENTATIVENESS OF SAMPLE STRATA}

\section{1:10 000000}

(C) EuroGeographics for the administrative boundaries Statistics Finland, Municipality-based statistical units, major regions 1:100 000, 2021

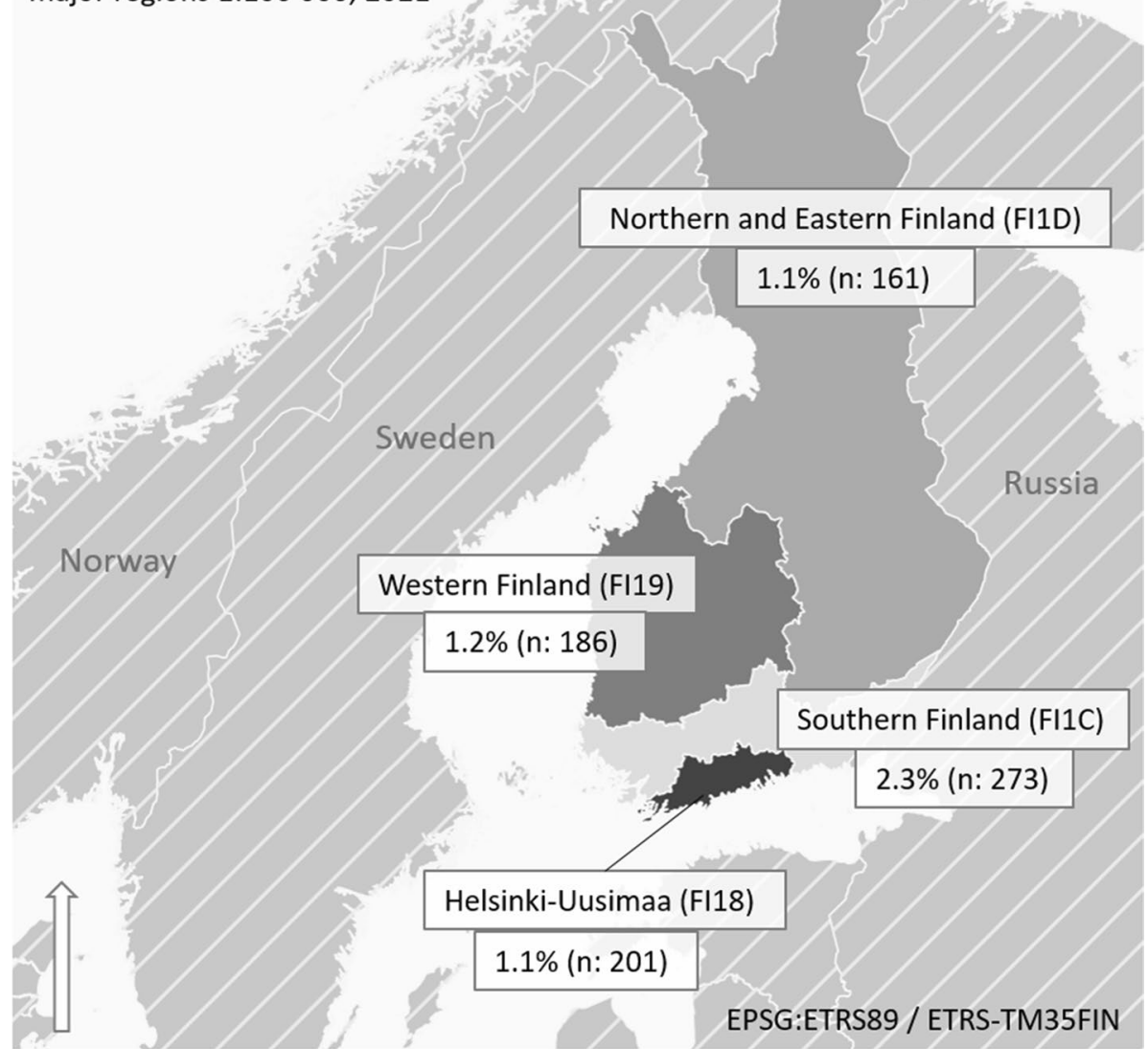

\section{All $6^{\text {th }}$ graders in 2017}

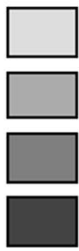

12101 (FI1C)

14724 (FI1D)

15067 (FI19)

17748 (FI18)
A\% (n: B)

A: Proportion of sampled students compared to all $6^{\text {th }}$ graders in the region

B: Sample size in the region

Fig. 1 Representativeness of the sample strata in each NUTS2-region in mainland Finland. Data on all sixth-grade students in 2017 obtained from the Municipality-based statistical units, Statistics Finland. The material was downloaded from Statistics Finland's interface service on 15 June 2021 with the licence $\underline{\text { CC }}$ BY 4.0 
parental consent, the children themselves made the final decision on participation. They were also informed of the confidentiality and possibility of discontinuing the survey at any point. The response rate of the whole sample was $80 \%(\mathrm{~N}=1075$ of $12-13$-years old). Our analytical sample only includes cases with no missing values in the variables of interest, $\mathrm{n}=821$.

The present article builds on a study of DBA that explored the effects of a few sociodemographic factors (age, gender, born in-country, three asset variables, and current country of living) on children's subjective well-being in 14 countries ( $\mathrm{N}: 34,512)$. They carried out the study with linear regression using three different subjective well-being scales as comparative outcome variables, including one context-free item (Overall Life Satisfaction scale) and two domain-specific scales.

While DBA detected some differences in the magnitude of the estimates across the wellbeing scales, all their analyses indicated that the current country of living contributed the most, and demographic variables (age, gender, born in-country) the least to well-being. Overall, DBA were able to explain 11-20\% of the variance in their outcome variables.

The present study continues from the DBA study and seeks to answer, (1) to what extent social capital, i.e. social networks, trust, and reciprocity, relates to young people's subjective well-being, and (2) whether the importance of these three dimensions vary at different points of the SWB distribution.

We have used the same modelling method and, to the extent possible, the same variables as DBA, only adding measures of social networks, reciprocity, and trust. However, there are some important differences to the original study. First, we used only two noncontextual well-being scales as our dependent variables. Furthermore, we focus on a single country (Finland) as opposed to a multi-country comparison, and thus dropped the variable of current country of living from the model. Lastly, we adopted both a parametric and a non-parametric analytical approach for the reasons explained below.

\subsection{Instruments}

\subsubsection{Dependent Variable}

Two different well-being scales were used. First, a context-free Overall Life Satisfaction scale (OLS-scale), based on a single question of "how satisfied are you with your life as a whole," with a response scale of 0-10 $(0=$ "completely dissatisfied", $10=$ "completely satisfied"), which was transformed to 0-100 scale. Young people's understanding of the question and the response scale was thoroughly pre-tested before the application (Dinisman \& Ben-Arieh, 2016).

Second, a reduced version of Huebner's Students' Life Satisfaction Scale (SLSS-scale), which is a composite indicator (Cronbach alpha 0.979) measuring cognitive subjective well-being with five statements: "My life is going well", "My life is just right", "I have a good life", "I have what I want in life" and "The things in my life are excellent" (Huebner, 1991; Diener et al., 1985). The sum of the original 11-point agreement scales $(0=$ "does not agree at all", $10=$ "fully agree") was transformed to $0-100$. 


\subsubsection{Social Capital}

The original ISCWeB-survey included several variables related to the dimensions of social networks and reciprocity, but social trust was not covered. Thus, a battery of questions related to trust was added to the Finnish questionnaire.

We used in total twelve variables to measure social capital, covering both close and somewhat more distant relationships (family, friends, and other acquaintances). Instead of combining the variables into fewer factors or composite indicators as some researchers have done, we kept them separate to distinguish the effects of networks, trust, and reciprocity respectively, and to discern the relative importance of family, friends, and other people. Because of the unavailability of data, we limit our attention to social capital accrued from live relationships, disregarding the admittedly important element of online social capital.

To measure social networks, we used ISCWeB-survey questions related to time used with different categories of people: "How often do you spend time relaxing, talking, or having fun with your family?", "How often do you see your friends when not at school?", "How often do you usually spend time playing sports or doing exercise in group (as opposed to alone)?", and "How often do you usually participate in hobbies or spare-time activities in group?" In the questionnaire, the last two questions were modified to specify whether the referred activities were done alone or in a group. For the analysis, the activities done in group were combined into one composite variable measuring "frequency of participation in hobbies in group". All these questions used a response scale ranging from $0=$ "never" to $5=$ "every day." One more frequent question about confidential relationships (see e.g. Rönkä et al., 2013) was added to the survey for the analysis of networks: "Do you currently have any close person, with whom you can talk about almost any personal matter" ( $0=$ "none", 3 = "several close persons").

In line with Putnam's theory, we understand reciprocity to refer to provision and reception of tangible and intangible forms of help, but the ISCWeB-survey only included questions related to reception of help. We used these as proxies for reciprocity: "If I have a problem, people in my family will help me", "If I have a problem, I have a friend who will support me", "If I have a problem at school, my teachers will help me", and "If I have a problem at school, other children will help me." The response scale of each ranged from $1=$ "disagrees" to $5=$ "fully agrees".

Social trust has been largely absent in the social capital research of youth, and it was neither included in the original ISCWeB-survey. Among adults, trust has often been measured with the question "would you say that most people can be trusted, or that you cannot be too careful in dealing with people" (e.g. Bjornskov 2006; Portela et al., 2013). We added the dimension of trust in the ISCWeB-questionnaire, by breaking the above question into several more concrete questions: "How strongly do you trust in (a) your family members, (b) friends, (c) neighbours, (d) schoolmates, (e) school personnel, (f) random passingby Finns, and (g) random passing-by foreigners. The response scale ranged from $0=$ "not at all" to $4=$ "very strongly". For the present analysis, four first ones were selected given their highest correlations with the well-being measures.

For comparability, all the social capital measures were standardized and used as continuous variables. 


\subsubsection{Control Variables}

To the extent possible, the variables included in DBA's models were used here as control variables: age, gender, and whether the person was born in the country (yes-no). A material deprivation index was included in substitution for the three possession dummies used by DBA. The index was composed of eight dummies asking whether the respondent possesses given material items (e.g. good clothes, access to the Internet at home, a mobile phone), and the scale ranged from $0=$ not deprived to $8=$ heavily deprived.

\subsection{Analysis}

Considering that the social capital variables were measured on an ordinal scale (although treated as continuous ones in the analyses ${ }^{5}$ ), both Pearson's correlations and Kruskal-Wallis nonparametric test were assessed. Both indicated significant associations between wellbeing variables and the included social capital variables (both test results available upon request), which justified their inclusion in the model. Most social capital variables also correlated moderately with each other (correlation coefficient ranging mostly between $\mathrm{r}$ : 20-30), yet without causing too high multicollinearity in the models (VIF $\leq 2.02$ ).

The analysis was carried out in three parts. First, the association between social capital and well-being (OLS-scale vs. SLSS-scale), was assessed with ordinary least squares linear regression. With both OLS-scale and SLSS-scale as dependent variables, five linear models were run; the first one only comprised the control variables (corresponding to the full model in DBA's analysis). Then, to assess the relative importance of each dimension of social capital, three models were run, each with the set of variables of one dimension of social capital added to the controls. The fifth model included all the variables at the same time. The magnitude of estimates and the coefficient of determination were compared between the models, as did DBA.

Second, a non-parametric approach was employed to check whether the predictors related differently to well-being at different points of the distribution of the outcome variable. This was done with a quantile regression analysis, but only using the SLSS-scale, which is a more truly continuous measure. To avoid conditioning the quantiles by the set of predictors, as does the more traditional conditional quantile regression, here unconditional quantile regression (UQR) was used, which divides the outcome variable into quantiles before the regression (Firpo et al., 2009; Killewald \& Bearak, 2014; Rios-Avila, 2020). Thus, the name "unconditional".

To interpret UQR results at an individual level, the assumption of rank invariance or rank similarity must remain true (Dong \& Shen, 2018; Gregg et al., 2019). The ISCWeBdata did not contain instrumental variables that would have allowed testing rank invariance/similarity. While we believe that social capital can move people from lower to higher ranks of wellbeing, we are rather confident that a one unit change in any one variable alone would not be sufficient to do so. Thus, we trust the assumption holds, and interpret the results at an individual level.

Third, the same analyses were carried out with a reversed and log-transformed SLSSscale for robustness check. As illustrated in Fig. 2, the original SLSS-scale was strongly

\footnotetext{
5 A test was conducted to compare models where social capital variables were treated as continues vs. ordinal ones. The one with continuous variables resulted in a better fit (BIC).
} 

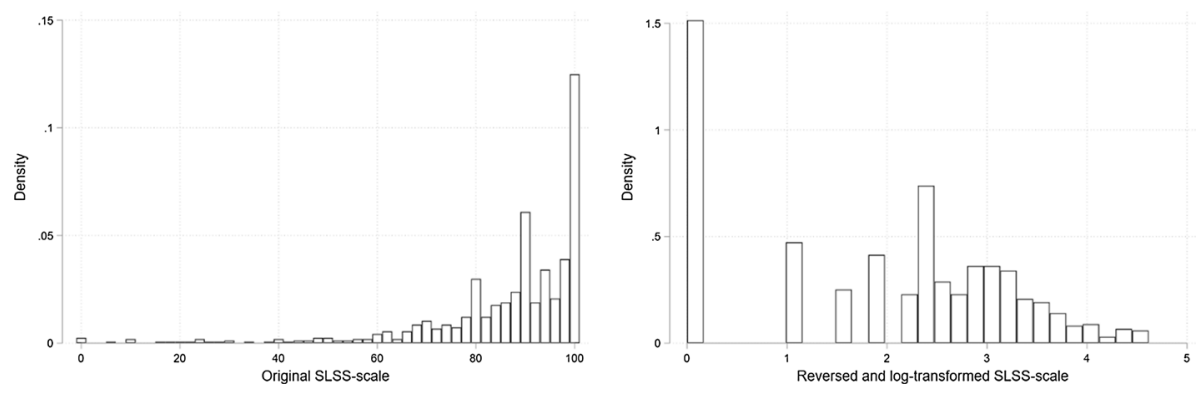

Fig. 2 Distribution of the original and the transformed SLSS-scales

left-skewed (skewness: -2.35 ; kurtosis: 10.06), and the Breusch-Pagan test after linear regression indicated severe heteroscedasticity $(p<0.000)$. Log-transformation of the reversed scale improved the issue but resulted nonetheless with a non-normal distribution (skew: - 0.29; kurtosis: 1.88). As the transformed SLSS-scale is not directly comparable with the work of DBA, and its interpretation is less intuitive because of the reversed scale, we only use it for robustness check of the results.

For the analysis, Stata 16.0 software was used. All analyses were carried out using case weight to reflect the stratified sampling strategy and the distribution of the young people between the strata. The case weight has been calculated so that the size of the weighted sample remains the same as that of the unweighted sample. For UQR, the Stata command "rifhdreg" was used, which accepts the same case weight to obtain results comparable to those of the linear regression (Rios-Avila, 2020).

The cross-sectional data design impedes claims about causality or direction of the association between the dependent and independent variables. However, the dominant postulation is that social capital impacts well-being rather than the other way around (e.g. Bae, 2019; Helliwell \& Putnam, 2004). Without being able to put this to test, we too have endorsed this assumption.

Table 1 presents descriptive statistics for the full sample and two extreme fractions of the SLSS distribution. The overall level of well-being in the sample is high with a mean score of 88 (median 90) on the OLS-scale and 86 (median 90) on the SLSS-scale. Approximately $46 \%$ of the sample scores full 100 on OLS-scale and 25\% score 100 on SLSS-scale, with variance 0.00 . A t-test comparing the mean values between the fractions revealed that there is significantly and systematically more social capital accumulated at the upper extreme of the well-being scale. It should be noted that these fractions are different from the quantiles in UQR analysis, which refer to specific points in the distribution instead of fractions.

\section{Results}

Tables 2 and 3 present the results of linear regression models. Similar to DBA, also here demographic and socioeconomic background variables alone have a limited share of the variance in well-being. Understandably, the present study shows even lower coefficients of determination for the baseline models than obtained by DBA (5-7\% against 11-20\%), given the different contexts. 
Table 1 Weighted descriptive statistics for full sample, and the youth with lowest vs. highest well-being level measured on SLSS-scale

\begin{tabular}{llll}
\hline Measures & Total sample mean (SE) & $\begin{array}{l}\text { Lowest 25\% of SLSS } \\
\text { mean (SE) }\end{array}$ & $\begin{array}{l}\text { Highest 25\% } \\
\text { on SLSS mean } \\
\text { (SE) }\end{array}$ \\
\hline $\begin{array}{l}\text { Dependent variables } \\
\text { OLS-scale }\end{array}$ & $88.13(0.69)$ & $68.37(1.80)$ & $99.58(0.14)$ \\
SLSS-scale & $86.27(0.66)$ & $64.19(1.51)$ & $100.00(0.00)$ \\
Independent variables networks & & & \\
Number of confidants & $2.24(0.04)$ & $1.69(0.07)$ & $2.59(0.06)$ \\
Freq. time spent with family & $3.19(0.05)$ & $2.24(0.10)$ & $3.87(0.08)$ \\
Freq. see friends & $2.82(0.05)$ & $2.57(0.10)$ & $3.12(0.09)$ \\
Freq. hobbies in group & $2.02(0.05)$ & $1.65(0.09)$ & $2.30(0.10)$ \\
Reciprocity & & & \\
Family helps with problems & $3.48(0.03)$ & $2.89(0.08)$ & $3.80(0.05)$ \\
Friends help with problems & $3.26(0.03)$ & $2.88(0.07)$ & $3.62(0.06)$ \\
Teachers help at school & $2.98(0.04)$ & $2.47(0.08)$ & $3.38(0.07)$ \\
Schoolmates help at school & $2.74(0.04)$ & $2.26(0.08)$ & $3.14(0.07)$ \\
Trust & & & \\
Trust in family & $3.66(0.02)$ & $3.13(0.07)$ & $3.96(0.01)$ \\
Trust in friends & $3.33(0.03)$ & $2.99(0.07)$ & $3.64(0.04)$ \\
Trust in neighbours & $1.93(0.04)$ & $1.33(0.08)$ & $2.49(0.08)$ \\
Trust om schoolmates & $2.45(0.04)$ & $1.84(0.07)$ & $3.03(0.06)$ \\
Control variables & & & \\
Age & $12.17(0.02)$ & $12.16(0.03)$ & $12.13(0.03)$ \\
Deprivation index & $0.2(0.02)$ & $0.43(0.06)$ & $0.06(0.02)$ \\
Proportion (SE) & & $59.32(3.60)$ & $48.25(3.69)$ \\
Gender (girls) & $56.31(1.83)$ & $94.70(1.59)$ & $95.50(1.50)$ \\
Born in country & $95.92(0.71)$ & 212 & \\
$\mathrm{n}$ & 821 & & \\
\hline & & & \\
\hline
\end{tabular}

The present study reveals that social capital adds considerably to the baseline model; it explains $38 \%$ of the variance in OLS-scale and $47 \%$ of the variance in SLSS-scale when adjusting for the control variables. Irrespective of the scale of the dependent variable, the dimension with the strongest association with well-being is trust, which alone explains $32-39 \%$ of the variance, followed by reciprocity (explaining $24-31 \%$ ) and then social networks (explaining 19-25\%). Most estimates of social capital variables decrease substantially when moving from unidimensional to multidimensional model (Models 2-4 vs. Model 5) due to correlation between social capital indicators. This finding underlines the importance of including the different dimensions of social capital in the same model to avoid overstated estimates caused by omitted variable bias.

Practically, all family-related variables are positive and strongly significant on both well-being scales and in every model. Moreover, the number of confidants is significant on both scales, and trust in schoolmates on SLSS-scale. The results show a largely similar pattern across the two well-being scales although the magnitude of the estimates varies to 
Table 2 Weighted linear regression on the association between social capital and overall life satisfaction (standardized coefficients)

\begin{tabular}{|c|c|c|c|c|c|}
\hline Overall life satisfaction & Model 1 & Model 2 & Model 3 & Model 4 & Model 5 \\
\hline Age & 0.775 & 1.770 & 0.749 & 1.580 & 1.660 \\
\hline Gender (ref. boys) & $-4.117 * *$ & $-4.618 * * *$ & $-5.171 * * *$ & $-3.240 * *$ & $-3.954 * * *$ \\
\hline Born in country (ref. "no") & 5.747 & 6.836 & 6.277 & 5.180 & 5.792 \\
\hline Deprivation index & $-7.551 * * *$ & $-4.540^{* *}$ & $-4.563 * * *$ & $-3.794 * *$ & $-2.679^{*}$ \\
\hline \multicolumn{6}{|l|}{ Networks } \\
\hline Freq. time spent with family & & $4.988 * * *$ & & & $1.619^{*}$ \\
\hline Freq. see friends & & 0.620 & & & 0.868 \\
\hline Number of confidants & & $5.016 * * *$ & & & $2.409 * * *$ \\
\hline Freq. hobbies in group & & 0.009 & & & -0.489 \\
\hline \multicolumn{6}{|l|}{ Reciprocity } \\
\hline Family helps with problems & & & $6.951 * * *$ & & $3.339 * * *$ \\
\hline Friend helps with problems & & & -0.050 & & -0.350 \\
\hline Schoolmates help & & & $2.228 * *$ & & 0.860 \\
\hline Teachers help at school & & & $2.326^{* *}$ & & 0.516 \\
\hline \multicolumn{6}{|l|}{ Trust } \\
\hline Trust in family & & & & $9.467 * * *$ & $6.476^{* * * *}$ \\
\hline Trust in friends & & & & 0.085 & -0.435 \\
\hline Trust in schoolmates & & & & 1.763 & 0.967 \\
\hline Trust in neighbours & & & & $1.704 *$ & 0.951 \\
\hline _cons & $77.184 * * *$ & $63.490 * * *$ & $76.924 * * *$ & $66.037 * * *$ & $64.854 * * *$ \\
\hline$N$ & 821 & 821 & 821 & 821 & 821 \\
\hline $\operatorname{Adj} . R^{2}$ & 0.073 & 0.261 & 0.311 & 0.392 & 0.451 \\
\hline $\operatorname{Adj} . R^{2}$ change from Model 1 & & 0.188 & 0.238 & 0.319 & 0.378 \\
\hline
\end{tabular}

${ }^{*} p<0.05, * * p<0.01, * * * p<0.001$

some extent. Overall, deemed by the adjusted R2-level, the SLSS-scale appears somewhat more sensitive to social capital.

UQR analysis (Table 4) revealed a slightly more complex picture. Because of zero-variance at the highest extreme of SLSS-scale (25\% of the respondents scored 100), the analysis was done only until the 75th quintile.

Most social capital variables get somewhat higher estimates in lower quantiles in comparison to the higher ones. The pattern is particularly notable concerning trust in family, help received from family, and number of confidants, all of which are positive and statistically significant in q-10, but not in q-75.

Overall, at the lower end of the scale, all family-related variables and the number of confidants are significant and positive. Interestingly, the frequency of participating in group hobbies is also significant but negative in q-10, while non-significant in any other quantiles.

At the upper end of the scale, time spent with family, trust in schoolmates, and access to teachers' help are positive and significant; time spent with family received the highest estimate but only slightly higher than that of trust in schoolmates.

Notably, there are some variables of each dimension of social capital that are significantly related to well-being at both ends of the distribution. For a comparison, UQR was 
Table 3 Weighted linear regression on the association between social capital and Student's life satisfaction scale (standardized coefficients)

\begin{tabular}{|c|c|c|c|c|c|}
\hline Students' life satisfaction scale & Model 1 & Model 2 & Model 3 & Model 4 & Model 5 \\
\hline Age & 0.937 & 1.909 & 0.943 & $1.829 *$ & $1.782 *$ \\
\hline Gender (ref. boys) & $-2.917 *$ & $-3.442 * *$ & $-4.306 * * *$ & $-2.062^{*}$ & $-3.093 * *$ \\
\hline Born in country (ref. "no") & 7.425 & $8.845^{*}$ & $8.046^{*}$ & 6.593 & $7.597 *$ \\
\hline Deprivation index & $-6.060^{* * *}$ & $-2.929 *$ & $-2.943^{* *}$ & $-2.050^{*}$ & -1.079 \\
\hline \multicolumn{6}{|l|}{ Networks } \\
\hline Freq. time spent with family & & $6.244 * * *$ & & & $2.706 * * *$ \\
\hline Freq. see friends & & 0.606 & & & 0.614 \\
\hline Number of confidants & & $4.667 * * *$ & & & $1.798 * * *$ \\
\hline Freq. hobbies in group & & -0.220 & & & -0.712 \\
\hline \multicolumn{6}{|l|}{ Reciprocity } \\
\hline Family helps with problems & & & $6.990 * * *$ & & $3.428 * * *$ \\
\hline Friend helps with problems & & & 0.518 & & 0.175 \\
\hline Schoolmates help & & & $2.285^{* *}$ & & 0.624 \\
\hline Teachers help at school & & & $3.081 * * *$ & & 1.115 \\
\hline \multicolumn{6}{|l|}{ Trust } \\
\hline Trust in family & & & & $9.459 * * *$ & $6.073 * * *$ \\
\hline Trust in friends & & & & 0.594 & 0.064 \\
\hline Trust in schoolmates & & & & $2.403^{* *}$ & $1.448^{*}$ \\
\hline Trust in neighbours & & & & $1.804^{* *}$ & 0.968 \\
\hline _cons & $70.738^{* * *}$ & $56.970 * * *$ & $70.102 * * *$ & $58.689 * * *$ & $58.847 * * *$ \\
\hline$N$ & 821 & 821 & 821 & 821 & 821 \\
\hline $\operatorname{Adj.} R^{2}$ & 0.052 & 0.298 & 0.363 & 0.443 & 0.517 \\
\hline $\operatorname{Adj} . R^{2}$ change from Model 1 & & 0.246 & 0.311 & 0.391 & 0.465 \\
\hline
\end{tabular}

${ }^{*} p<0.05, * * p<0.01, * * * p<0.001$

also run only with the control variables (not shown here) to calculate the difference in adjusted R2-values. According to these results, social capital variables weigh considerably more for well-being at the lower end of the scale.

In Fig. 3, UQR estimates are plotted separately for each social capital variable. For comparison, linear regression estimates are plotted in the same graphs with constant horizontal lines. The overlapping confidence intervals show that most of the results do not differ significantly between linear and quantile regression models, except for those of trusting in one's family. Its importance is significantly greater at the lower end of SLSS-distribution. Moreover, confidence intervals of receiving help from family, and the number of confidants are at the limit of statistical significance. Such differences go unnoticed in the linear models.

A robustness check of the linear regression results was run using reversed and log-transformed SLSS-scale as the dependent variable (results available upon request). Although the sign and the magnitude of the estimates obviously changed, the significance level matched largely with those obtained with the untransformed SLSS-scale. Only, the number of confidants did not turn significant on the transformed scale, whereas help received from teachers did. The most notable difference was found in the coefficient of determination; the 


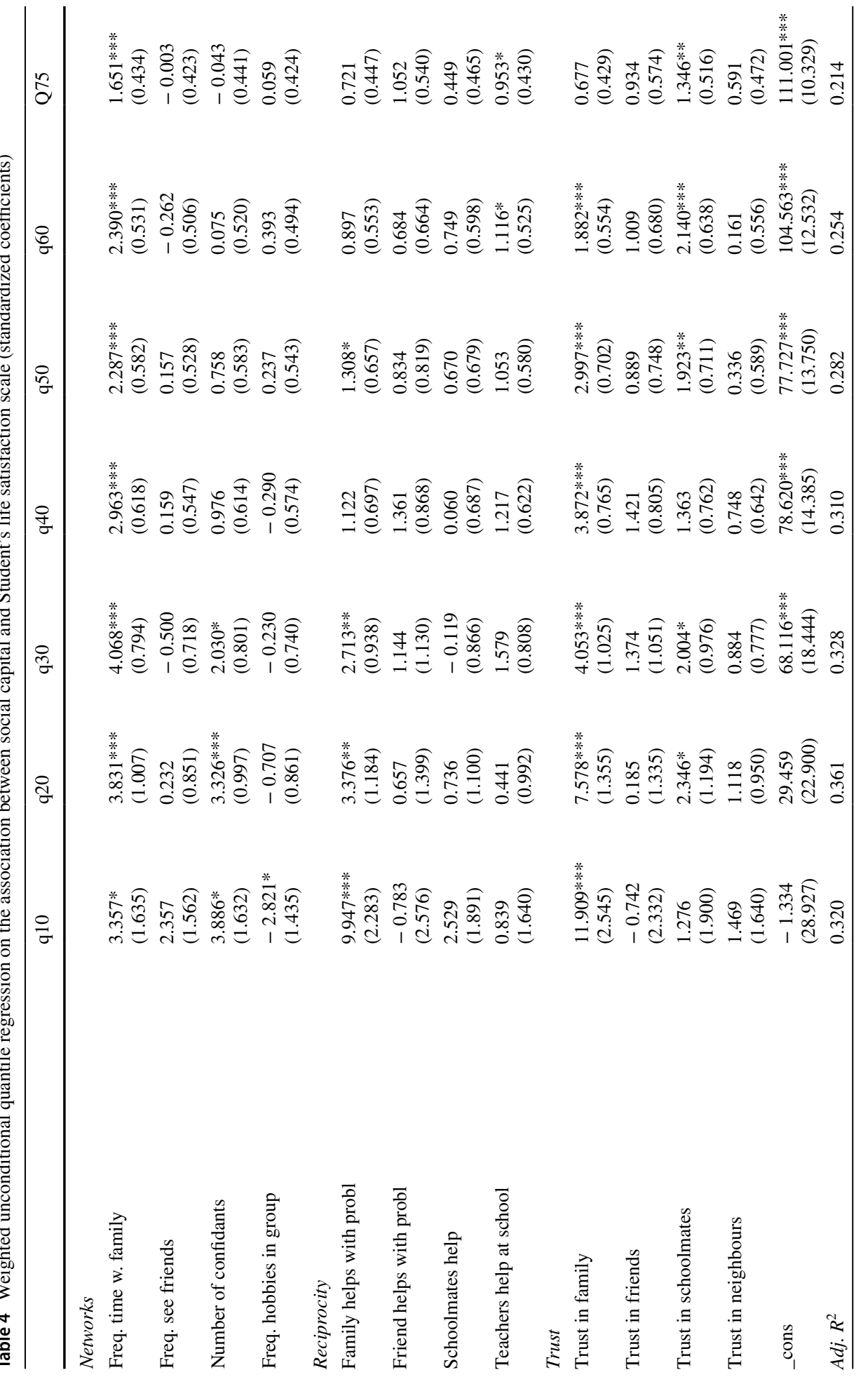




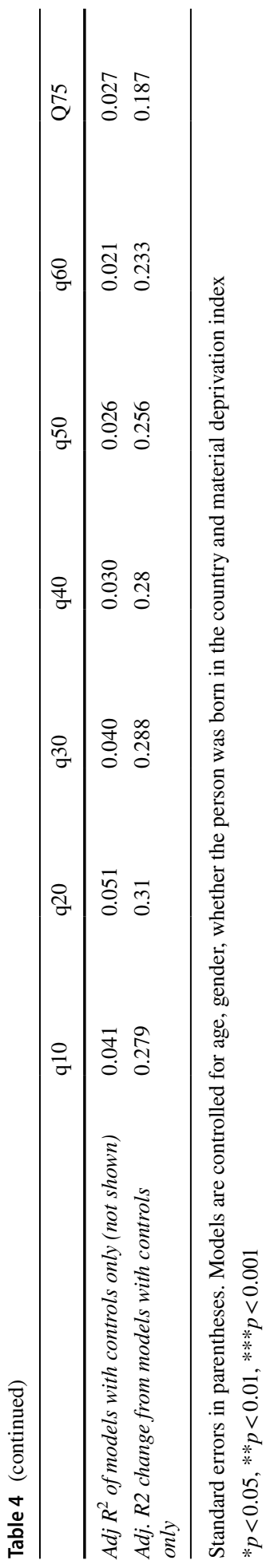



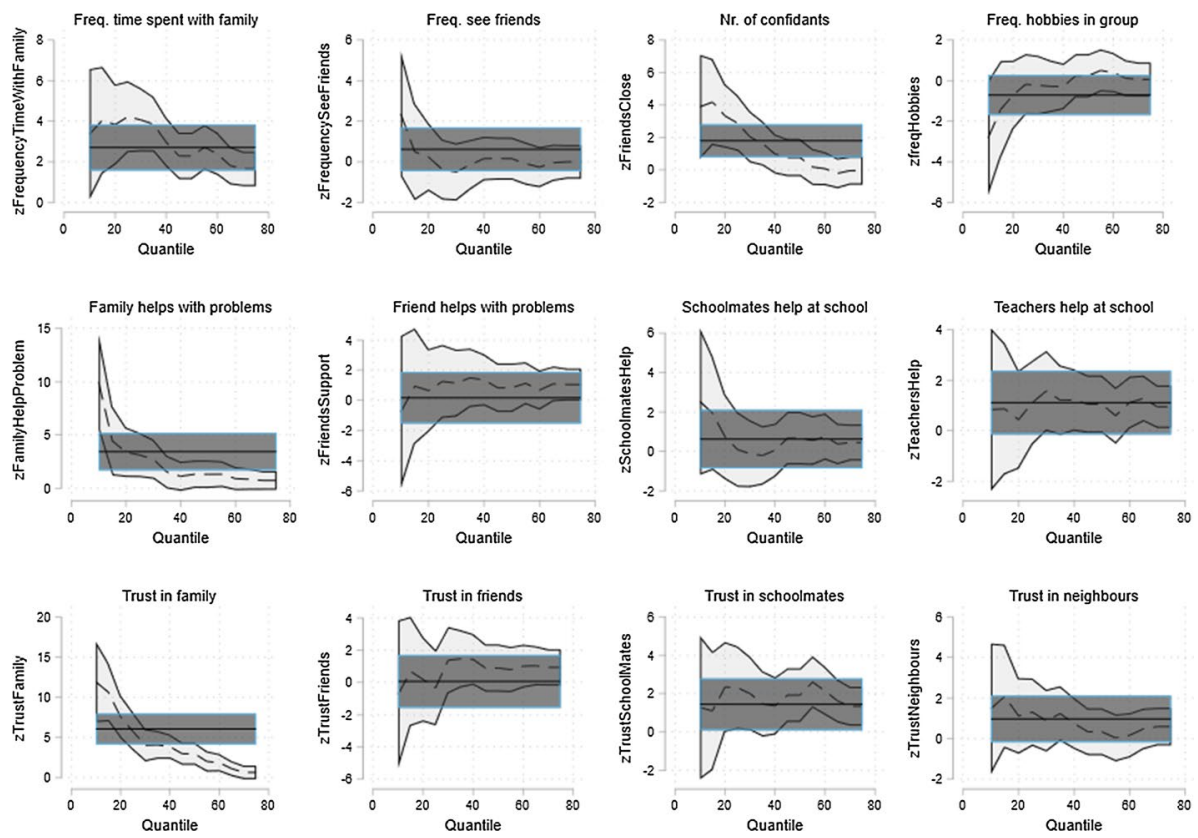

Fig. 3 Results of ordinary linear regression (dark grey) and unconditional quantile regression (light grey) with $95 \%$ confidence intervals

full set of social capital indicators explained less of the variance in the transformed SLSSscale than in the untransformed one (36\% vs. $47 \%)$.

UQR results with the transformed SLSS-scale were equally similar to those obtained with the untransformed scale in terms of statistical significance. Among the main differences, frequency of participating in group hobbies turned non-significant for those with most frail well-being, and for those best-off, help received from friends turned significant instead of help received from teachers. Most importantly, the dominant pattern observed with the untransformed scale where those with the faintest well-being level obtained many of the highest estimates, was no longer observed when using the transformed scale. Yet, the adjusted R2-values indicated even more clearly that social capital matters more for the wellbeing of those who otherwise fare poorly.

\section{Discussion}

This paper explores the relationship between social capital and subjective well-being among young people using Finland's subsample of Children's Worlds survey. We relied on Putnam's theoretical framework and assessed the relative contribution of social networks, social trust, and reciprocity, separately and jointly, to subjective well-being of early adolescents. Our results indicate that all three dimensions of social capital are strongly related to well-being, jointly explaining $38-47 \%$ of the variance in adolescents' well-being. Of the three dimensions, social trust generates the strongest effect. These results were largely confirmed by robustness check with a reversed and log-transformed well-being scale, although 
the importance of social capital for wellbeing appeared somewhat lower (36\% vs. $47 \%$ of the variance in wellbeing). In comparison to sociodemographic variables (age, gender, born in country, deprivation index), social capital expands manifold our understanding of well-being.

Family-related variables showed the strongest association with well-being while relationships with friends, schoolmates, teachers, and other people mattered considerably less. Other researchers have noted that the importance of family tends to reduce gradually at the same pace as the importance of friends increases (Ahlborg et al., 2019). However, our cross-sectional dataset with only $12-13$ years old adolescents did not allow us to verify changes over time.

Our findings converge largely with previous research, which also has found a significant positive effect of young people's social capital on their wellbeing. However, we have argued that previous research has possibly overstated the importance of social capital when it has focused on one dimension of social capital only. We approached social capital as a multidimensional resource consisting of networks, trust, and reciprocity. Alike Putnam (2000) and Lin and Fu (2003), we too observed a moderate correlation between the three dimensions. In multivariate analyses, the magnitude of regression estimates decreased when a unidimensional model was expanded to a multidimensional one. Our findings therefore underline the importance of including all social capital dimensions in the same model to avoid omitted variable bias.

We explored the association of social capital with well-being using two context-free well-being scales: a one-dimensional OLS-scale and a five-dimensional SLSS-scale. We considered it important to avoid domain-specific outcome variables, which might cause tautological results if very similar variables are included as explanatory and outcome variables. The two well-being scales produced similar results both in terms of statistical significance and magnitude of estimates. Small differences were noted, but only at $p<0.05$ level; a more conservative interpretation with $p<0.001$ resulted in very similar results across the two scales. Overall, the SLSS-scale appeared somewhat more sensitive to the effects of social capital, but the OLS-scale did not fall far behind. Moreover, given the greater time-effectiveness of gathering data for OLS-scale (one question vs. five questions), it can be considered as a satisfactory measure of well-being, especially if using a more stringent confidence level.

Much of previous well-being research has relied on parametric methods without verifying whether the methodological assumptions are met. Finland has repeatedly scored as one of the happiest countries in the world and is therefore one of the most extreme cases for happiness/well-being research. Due to heavily left-skewed well-being scales, we employed both a parametric and a non-parametric approach, using linear and unconditional quantile regression to discern potential differences in the way social capital relates to well-being at different points of the well-being scale. Our descriptive results showed that young people with low levels of well-being possess significantly less social capital than youth with higher levels of well-being. Quantile regression results largely coincided with those of linear regression indicating that all the three social capital dimensions were significant predictors of well-being across the quantiles, and that intra-family relationships were the strongest predictors of well-being at every quantile. Measuring with the original SLSS-scale, quantile regression suggested that the importance of family relationships was greatest for those whose well-being was low, but the robustness test with reversed and log-transformed wellbeing scale found that family ties matter equally across the quantiles. Yet, social capital as a whole weighs considerably more for those whose well-being level is low. These results support Putnam's proposition that at-risk-children who possess the least of social capital, 
can gain most if their social capital is increased (Putnam, 2000). In the present study, this observation would have gone unnoticed if only analysed with ordinary linear regression. However, more studies are needed to confirm these results.

Social capital is a multifaceted asset with inherently intertwined dimensions. Therefore, to analyse any presumed outcome of it, one should consider all its dimensions concurrently. We have taken one step in that direction. However, our social capital measurement had some important limitations. Reflecting on Lin's (2003) recommendation of contextualizing social capital variables, the ones available in ISCWeB may have been too generic for measuring social networks. Because of the unavailability of data, our dimension of reciprocity was only covered from the perspective of receiving help but lacked the other equally important dimension of the provision of help. Moreover, although the new trustrelated questions were pre-tested in advance, these should be validated with different age groups. Further, limited by its cross-sectional design and focus on one country, our study cannot establish any claims about causality or inter-cultural validity of the results.

Longitudinal studies on young people's social capital are scarce but important. If we can prove the causal link between young people's social capital and well-being, the relevant next step will be to consider how to support social capital accumulation. No doubt, schools are best placed to bolster social network building, trust in other people, and reciprocity, even among those young people whose home environment does not provide strong social capital. Embracing, at all levels, the strengthening of social capital as a permanent part of the educational programme could be one of the best investments in the future well-being of young people.

\section{Appendix 1}

(See Table 5). 


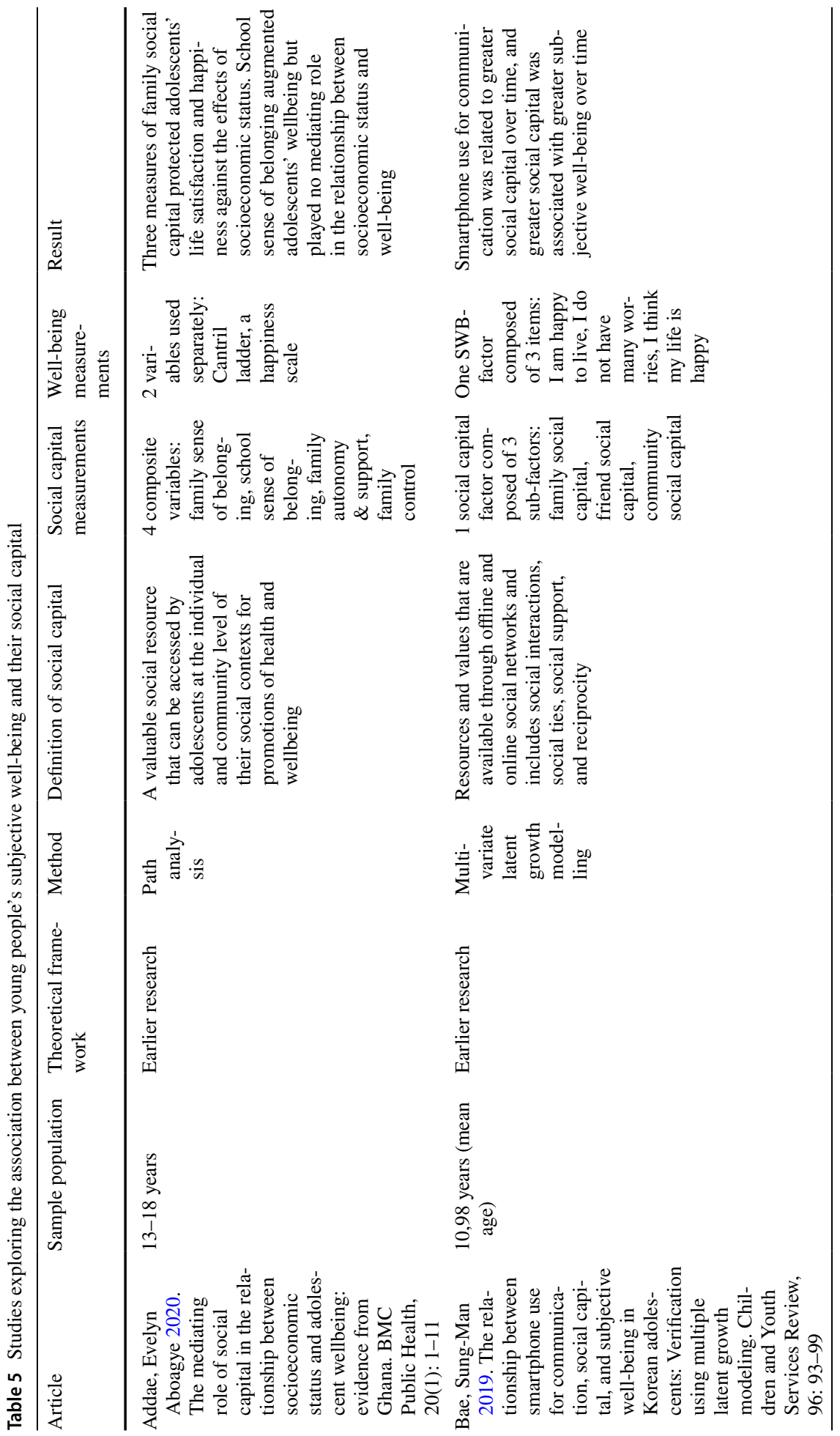




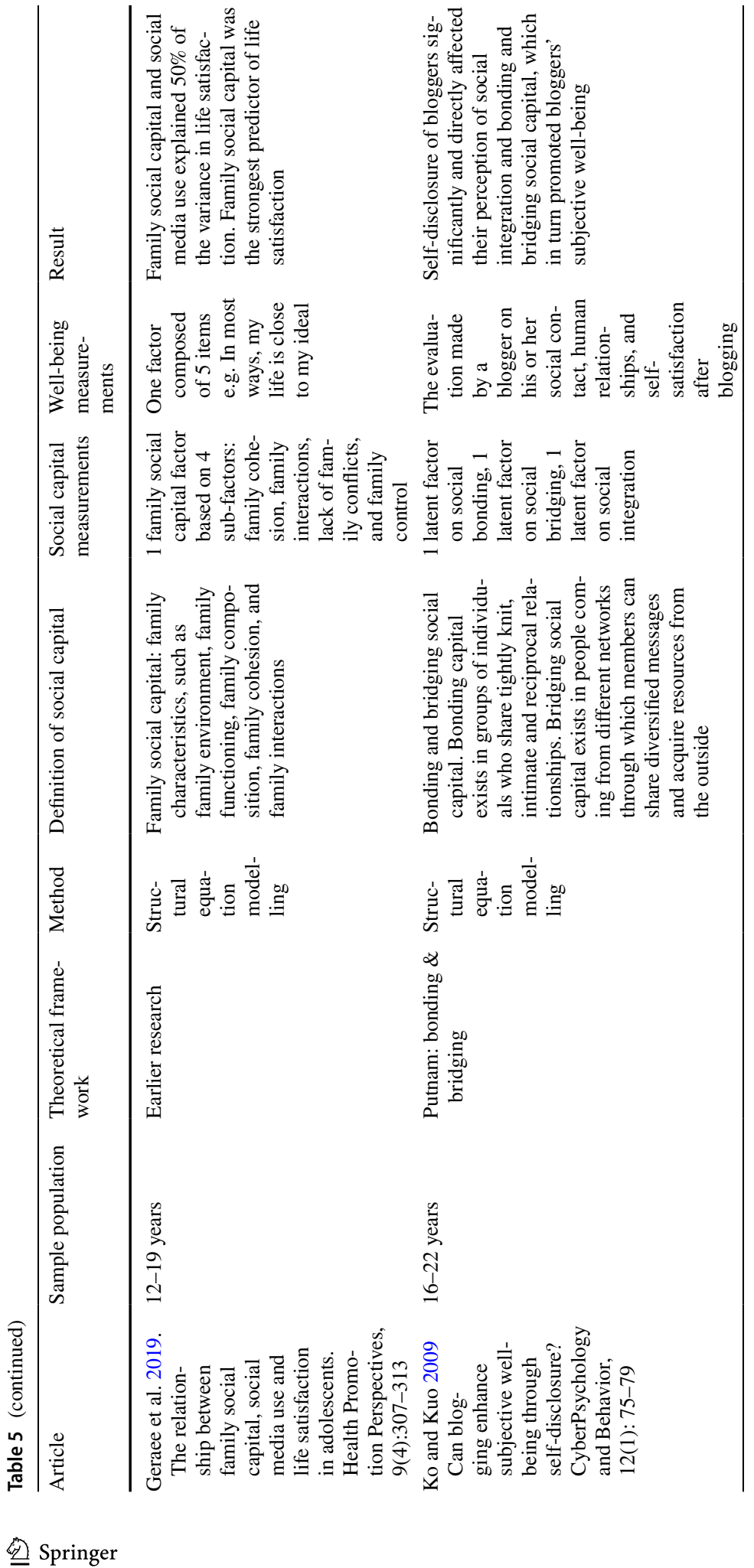




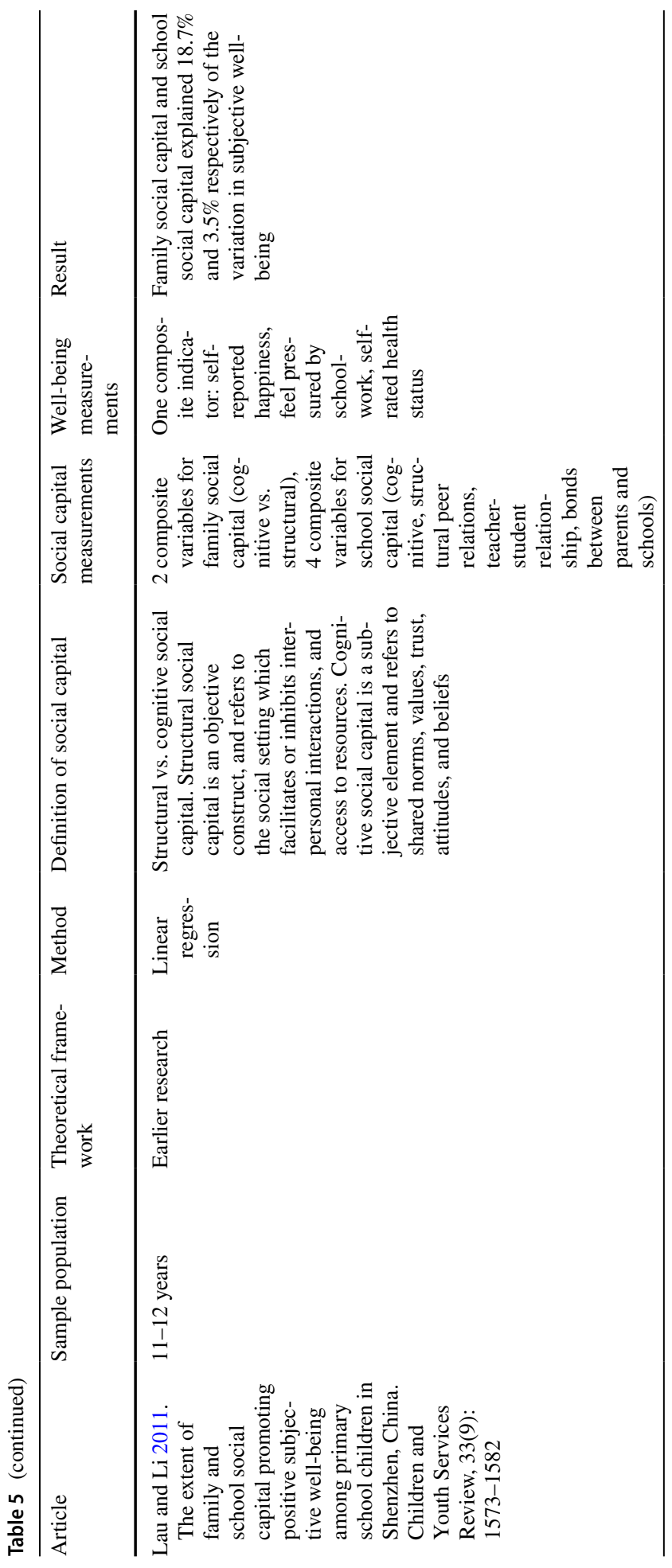




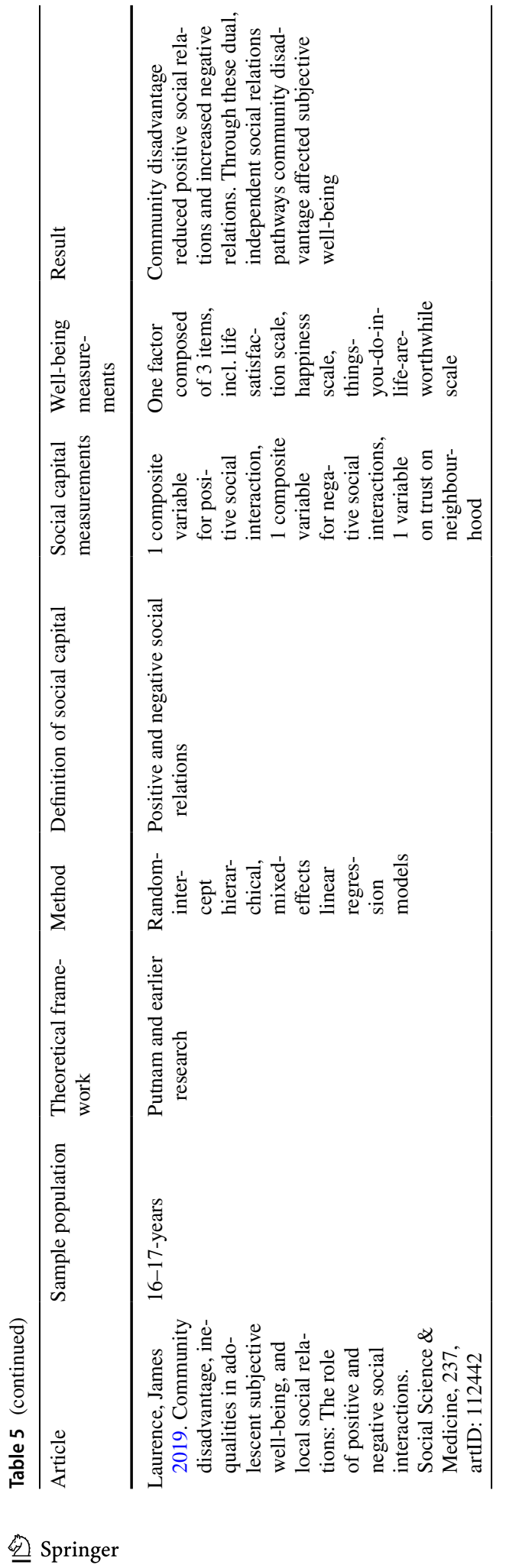




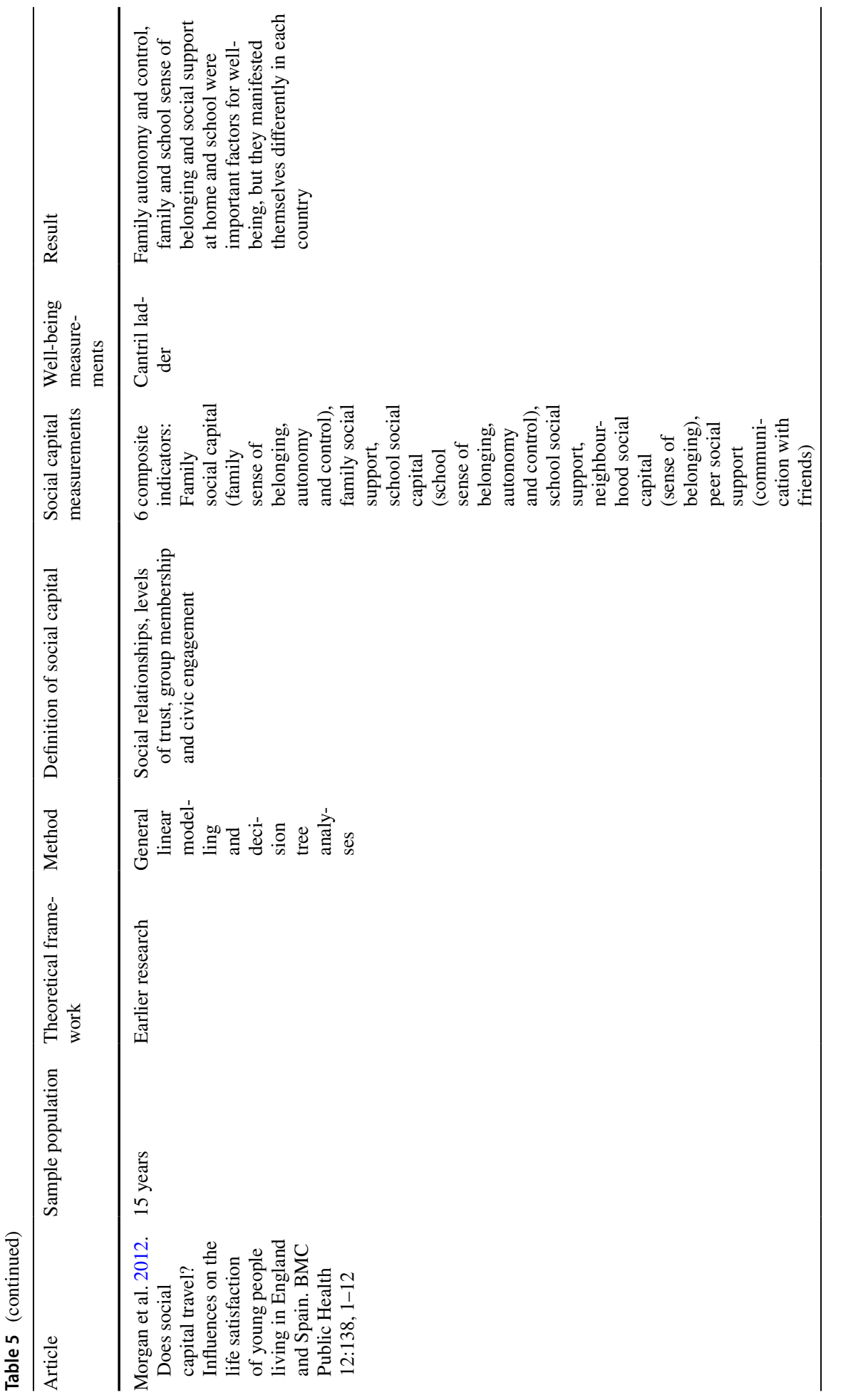




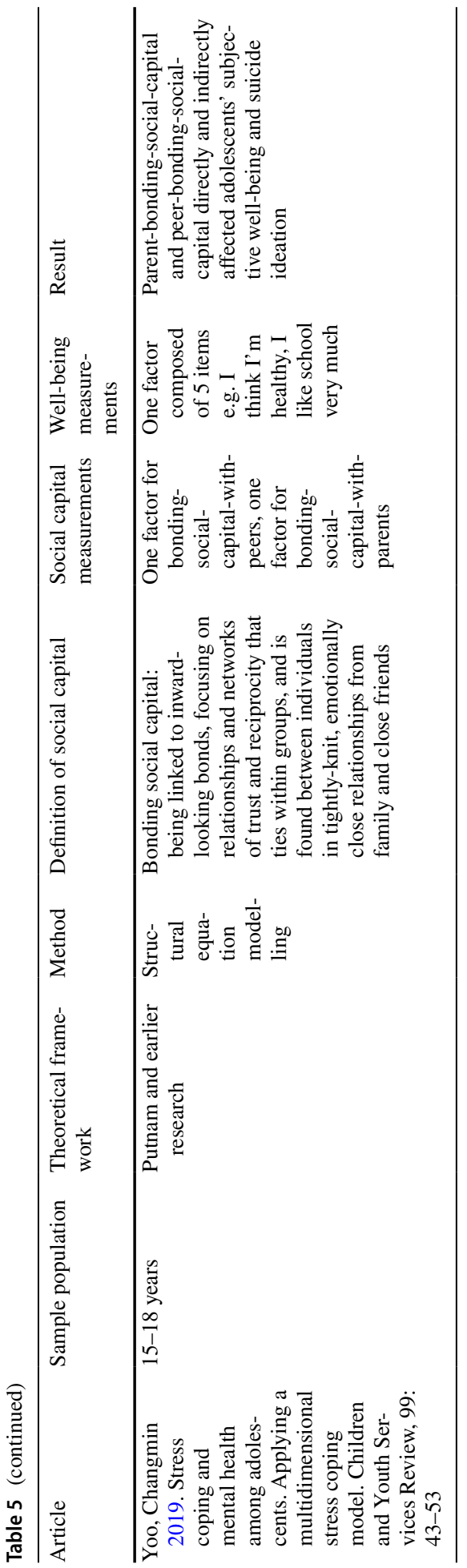


Acknowledgements We are grateful to Fernando Rios-Avila (Ph.D.), Levy Economics Institute of Bard College (US) for his generous advice on the technicalities related to quantile regression on Stata. We are equally grateful to Petra Kollanen (BS) and Venla Aaltonen (MS), Geography department, University of Turku (Finland) for their unhesitating readiness to draw the map (figure) included in the article. This research was partially supported by the INVEST Research Flagship. Any errors in the document are our own.

Author Contributions Minna Tuominen: main author writing the manuscript, in charge of the analysis and interpretation of the results. Leena Haanpää: In charge of the data gathering in Finland; co-author directly contributing to the chapters of previous research, and data and methods; also, contributing to the interpretation of the results and commenting every version of the manuscript.

Funding Open access funding provided by University of Turku (UTU) including Turku University Central Hospital. This research was partly funded by the Academy of Finland Flagship Programme (Decision Number: 320162) and the Turku University Foundation (Decision Number: c47286).

Availability of Data and Material The data on the third wave of the International Survey of Children's WellBeing will become openly accessible in June 2021. The first two waves of the survey are freely accessible at www.isciweb.org

\section{Code Availability Stata 16.0, SPSS 25.}

\section{Declarations}

Conflict of interest The authors declare that they have no conflict of interest.

Open Access This article is licensed under a Creative Commons Attribution 4.0 International License, which permits use, sharing, adaptation, distribution and reproduction in any medium or format, as long as you give appropriate credit to the original author(s) and the source, provide a link to the Creative Commons licence, and indicate if changes were made. The images or other third party material in this article are included in the article's Creative Commons licence, unless indicated otherwise in a credit line to the material. If material is not included in the article's Creative Commons licence and your intended use is not permitted by statutory regulation or exceeds the permitted use, you will need to obtain permission directly from the copyright holder. To view a copy of this licence, visit http://creativecommons.org/licenses/by/4.0/.

\section{References}

Addae, E. A. (2020). The mediating role of social capital in the relationship between socioeconomic status and adolescent well-being: Evidence from ghana. BMC Public Health, 20, 20.

Ahlborg, M. G., Svedberg, P., Nyholm, M., Morgan, A., \& Nygren, J. M. (2019). Into the realm of social capital for adolescents: A latent profile analysis. PloS One, 14(2), e0212564.

Bae, S.-M. (2019). The relationship between smartphone use for communication, social capital, and subjective well-being in korean adolescents: Verification using multiple latent growth modeling. Children and Youth Services Review, 96, 93-99.

Bjørnskov, C. (2006). The multiple facets of social capital. European Journal of Political Economy, 22(1), $22-40$.

Bourdieu, P. (1986). The forms of capital. In J. E. Richardson (Ed.), Handbook of theory of research for the sociology of education (pp. 241-258). Greenwood Press.

Campbell, A., Converse, P. E., \& Rodgers, W. L. (1976). Quality of American life. perceptions, evaluations, and satisfactions. New York: Russell Sage Foundation.

Choudhury, S., Blakemore, S.-J., \& Charman, T. (2006). Social cognitive development during adolescence. Social Cognitive and Affective Neuroscience, 1(3), 165-174.

Coleman, J. C., \& Hendry, L. B. (1999). The nature of adolescence (3rd ed.). Routledge.

Coleman, J. S. (1988). Social capital in the creation of human capital. American Journal of Sociology, 94, 95-120.

Coleman, J. S., \& Hoffer, T. (1987). Public and private high schools. The impact of communities. New York: Basic Books.

Diener, E. (1984). Subjective well-being. Psychological Bulletin, 95(3), 542-575. 
Diener, E., Emmons, R. A., Larsen, R. J., \& Sharon, G. (1985). The satisfaction with life scale. Journal of Personality Assessment, 49(1), 71.

Dinisman, T., \& Ben-Arieh, A. (2016). The characteristics of children's subjective well-being. Social Indicators Research, 126(2), 555-569.

Dong, Y., \& Shen, S. (2018). Testing for rank invariance or similarity in program evaluation. The Review of Economics and Statistics, 100(1), 78-85.

Farrell, C. (2007). Thinking critically about social capital. Irish Journal of Sociology, 16(2), 27-49.

Ferguson, K. M. (2006). Social capital and children's well-being: A critical synthesis of the international social capital literature. International Journal of Social Welfare, 15, 2-18.

Firpo, S., Fortin, N. M., \& Lemieux, T. (2009). Unconditional quantile regression. Econometrica, 77(3), 953-973.

Furstenberg, Jr, F. F., \& Hughes, M. E. (1995). Social capital and successful development among at-risk youth. Journal of Marriage and Family, 57, 580-592.

Garbarino, J., \& Sherman, D. (1980). High-risk neighborhoods and high-risk families: The human ecology of child maltreatment. Child Development, 51(1), 188-198.

Geraee, N., Eslami, A. A., \& Soltani, R. (2019). The relationship between family social capital, social media use and life satisfaction in adolescents. Health Promotion Perspectives, 9(4), 307-313.

Granovetter, M. S. (1973). The strength of weak ties. American Journal of Sociology, 78(6), 1360-1380.

Gregg, P., Macmillan, L., \& Vittori, C. (2019). Intergenerational income mobility: Access to top jobs, the low-pay no-pay cycle, and the role of education in a common framework. Journal of Population Economics, 32, 501-528.

Haanpää, L., Kuula, M., \& Hakovirta, M. (2019). Social relationships, child poverty, and children's life satisfaction. Social Sciences, 8(2), 35.

Helliwell, J. F., Huang, H., Wang, S., \& Norton, M. (2020). Social environments for world happiness. In J. F. Helliwell, R. Layard, J. Sachs, \& J.-E. de Neve (Eds.), World happiness report 2020 Sustainable Development Solutions Network (pp. 13-46).

Helliwell, J. F., \& Putnam, R. D. (2004). The social context of well-being. Philosophical Transactions of the Royal Society of London Series B, 359, 1435-1446.

Huebner, E. S. (1991). Further validation of the students' life satisfaction scale: The independence of satisfaction and affect ratings. Journal of Psychoeducational Assessment, 9(4), 363-368.

Jenkins, L. N., \& Fredrick, S. S. (2017). Social capital and bystander behavior in bullying: Internalizing problems as a barrier to prosocial intervention. Journal of Youth and Adolescence, 46(4), 757-771.

Killewald, A., \& Bearak, J. (2014). Is the motherhood penalty larger for low-wage women? A comment on quantile regression. American Sociological Review, 79(2), 350-357.

Ko, H.-C., \& Kuo, F.-Y. (2009). Can blogging enhance subjective well-being through self-disclosure? Cyberpsychology \& Behavior, 12(1), 75-79.

Lau, M., \& Li, W. (2011). The extent of family and school social capital promoting positive subjective wellbeing among primary school children in Shenzhen China. Children and Youth Services Review, 33(9), $1573-1582$.

Laurence, J. (2019). Community disadvantage, inequalities in adolescent subjective well-being, and local social relations: The role of positive and negative social interactions. Social Science \& Medicine, 237, 1124-1142.

Leme, V. B. R., Del Prette, Z. A. P., \& Coimbra, S. (2015). Social skills, social support and well-being in adolescents of different family configurations. Paidéia Cadernos De Psicologia E Educação, 25(60), 9-17.

Lin, N., \& Fu, Y-C. (2003). Social capital: Social resources, civic engagement or trust? In Annual meeting of the American sociological association.

Lindfors, P., Minkkinen, J., Rimpelä, A., \& Hotulainen, R. (2018). Family and school social capital, school burnout and academic achievement: A multilevel longitudinal analysis among finnish pupils. International Journal of Adolescence and Youth, 23(3), 368-381.

Lindström, M., \& Giordano, G. N. (2016). The 2008 financial crisis: Changes in social capital and its association with psychological well-being in the United Kingdom-A panel study. Social Science \& Medicine, 153, 71-80.

Maccoby, E. E., Johnson, J. P., \& Church, R. M. (1958). Community integration and the social control of juvenile delinquency. Journal of Social Issues, 14, 38-51.

Mauss, M. (1990). The gift: The form and reason for exchange in archaic societies. Routledge.

Morgan, A. R., Rivera, F., Moreno, C., \& Haglund, B. J. A. (2012). Does social capital travel? Influences on the life satisfaction of young people living in England and Spain. BMC Public Health, 12(138), 1-12.

Ottova-Jordan, V., Inese G., \& Joanna M. (2016). Positive health: Life satisfaction. In I. Jo, C. Dorothy, Y. Taryn, S. Oddrun, T. Torbjorn, A. Lise, M. Frida, et al. (Ed.), Growing up unequal: Gender and 
socioeconomic differences in young people's health and well-being (pp. 75-98). Copenhagen: World Health Organization (Health Policy For Children And Adolescents, No. 7).

Parker, J. G., \& Asher, S. R. (1993). Friendship and friendship quality in middle childhood: Links with peer group acceptance and feelings of loneliness and social dissatisfaction. Developmental Psychology, 29(4), 611-621.

Portela, M., Neira, I., \& del Mar Salinas-Jiménez, M. (2013). Social capital and subjective wellbeing in Europe: A new approach on social capital. Social Indicators Research, 114(2), 493-511.

Portes, A. (1998). Social capital: Its origins and applications in modern sociology. Annual Review of Sociology, 24(1), 1-24.

Portes, A. (2000). The two meanings of social capital. Sociological Forum, 15(1), 1.

Putnam, R. D. (2000). Bowling alone: The collapse and revival of American community. Simon \& Schuster.

Putnam, R. D., Leonardi, R., \& Nanetti, R. Y. (1993). Making democracy work: Civic traditions in modern Italy. Princeton University Press.

Rees, G. (2017). Children's views on their lives and well-being. Findings from the Children's worlds project. In Children's well-being: Indicators and Research. London: Springer.

Rios-Avila, F. (2020). Recentered influence functions (RIFs) in stata: RIF regression and RIF decomposition. The Stata Journal, 20(1), 51-94.

Rodríguez-Pose, A., \& von Berlepsch, V. (2014). Social capital and individual happiness in Europe. Journal of Happiness Studies, 15(2), 357-386.

Rönkä, A. R., Rautio, A., Koiranen, M., Sunnari, V., \& Taanila, A. (2013). Experience of loneliness among adolescent girls and boys: Northern finland birth cohort 1986 study. Journal of Youth Studies, 17(2), 183.

Rothstein, B., \& Stolle, D. (2002). How political institutions create and destroy social capital: An institutional theory of generalized trust. In 98th Meeting of the American Political Science Association. Boston, MA.

Runyan, D. K., Hunter, W. M., Socolar, R. R. S., Amaya-Jackson, L., English, D., Landsverk, J., et al. (1998). Children who prosper in unfavorable environments: The relationship to social capital. Pediatrics, 101(1), 12-18.

Sampson, R. J., Morenoff, J. D., \& Earls, F. (1999). Beyond social capital: Spatial dynamics of collective efficacy for children. American Sociological Review, 64, 633-660.

Siisiäinen, M. (2003). Yksi käsite, kaksi lähestymistapaa: Putnamin ja bourdieun sosiaalinen pääoma. Sosiologia, 3, 204-218.

Stevenson, H. C. (1998). Raising safe villages: Cultural-ecological factors that influence the emotional adjustment of adolescents. Journal of Black Psychology, 24(1), 44-59.

Webster, D., Dunne, L., \& Hunter, R. (2021). Association between social networks and subjective wellbeing in adolescents: A systematic review. Youth \& Society, 53(2), 175-210.

Yoo, C. (2019). Stress coping and mental health among adolescents: Applying a multidimensional stress coping model. Children and Youth Services Review, 99, 43-53.

Publisher's Note Springer Nature remains neutral with regard to jurisdictional claims in published maps and institutional affiliations. 